\title{
Correction to: Could stock hedge Bitcoin risk(s) and vice versa?
}

\section{David Iheke Okorie ${ }^{1}$}

Published online: 25 September 2019

(c) Springer Nature Switzerland AG 2019

\section{Correction to: Digital Finance https://doi.org/10.1007/s42521-019-00011-0}

There were some inconsistencies in Tables 4, 5, and 7 in the online PDF. The corrected Tables 4, 5 and 7 are given below. The original article has been corrected.

The original article can be found online at https://doi.org/10.1007/s42521-019-00011-0.

David Iheke Okorie

okorie.davidiheke@gmail.com

1 Wang Yanan Institute for Studies in Economics (WISE), Xiamen University, N106, Economics Building (WISE\&SOE), 422 South Siming Road, Xiamen 361005, China 


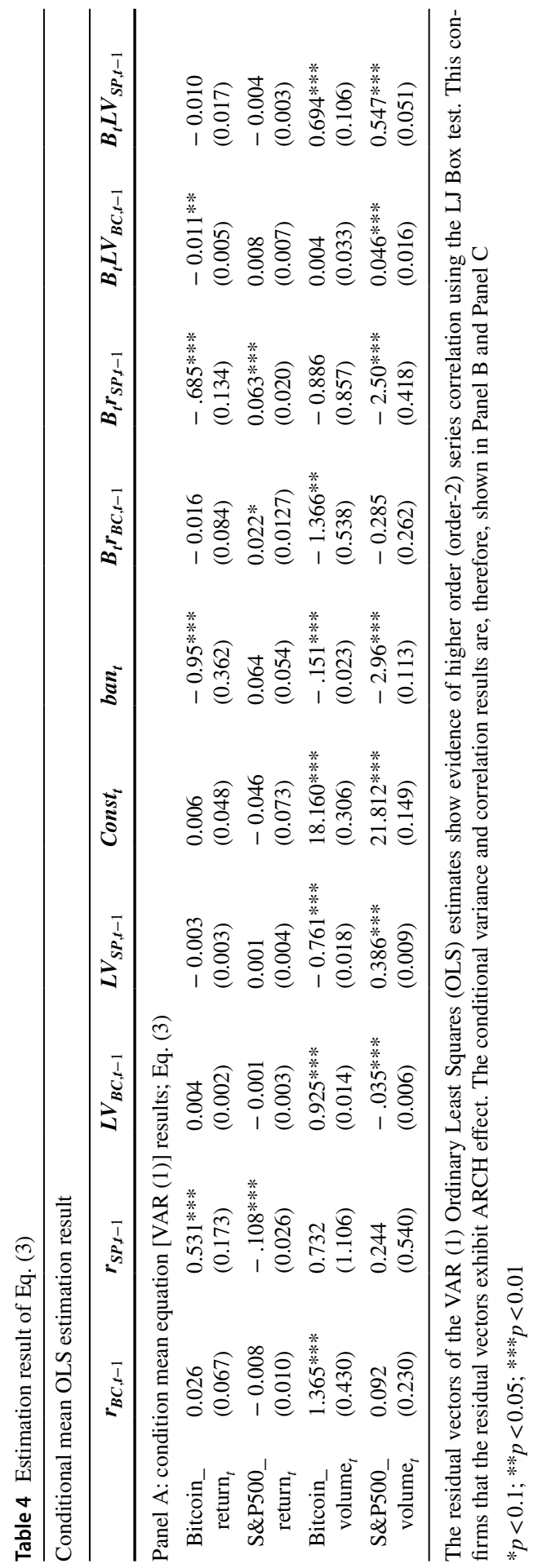




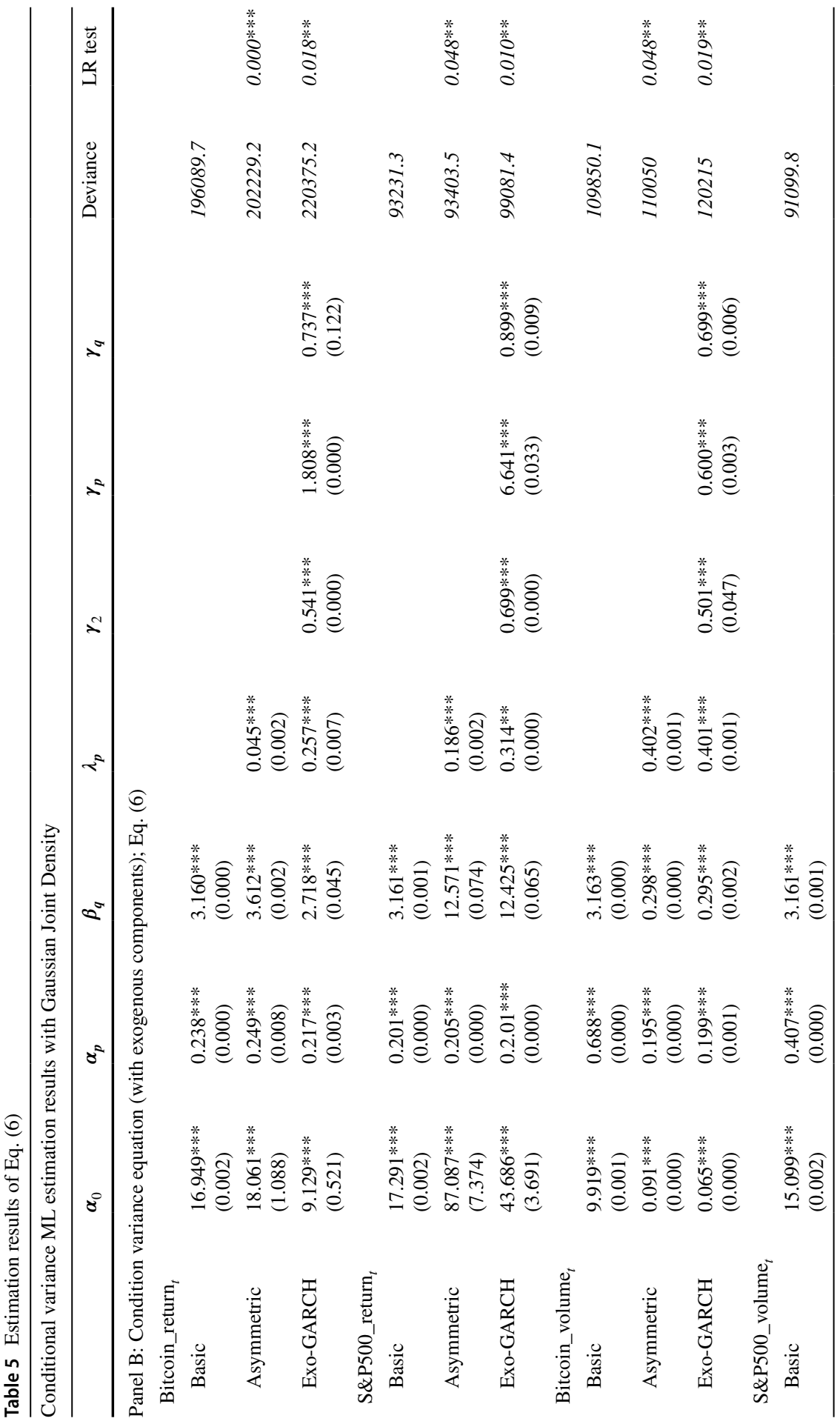




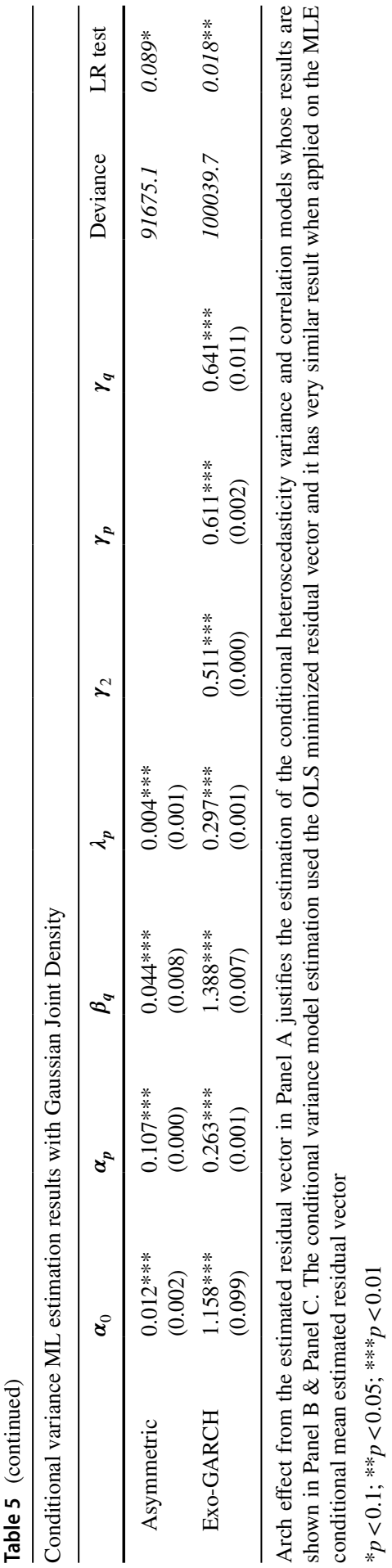




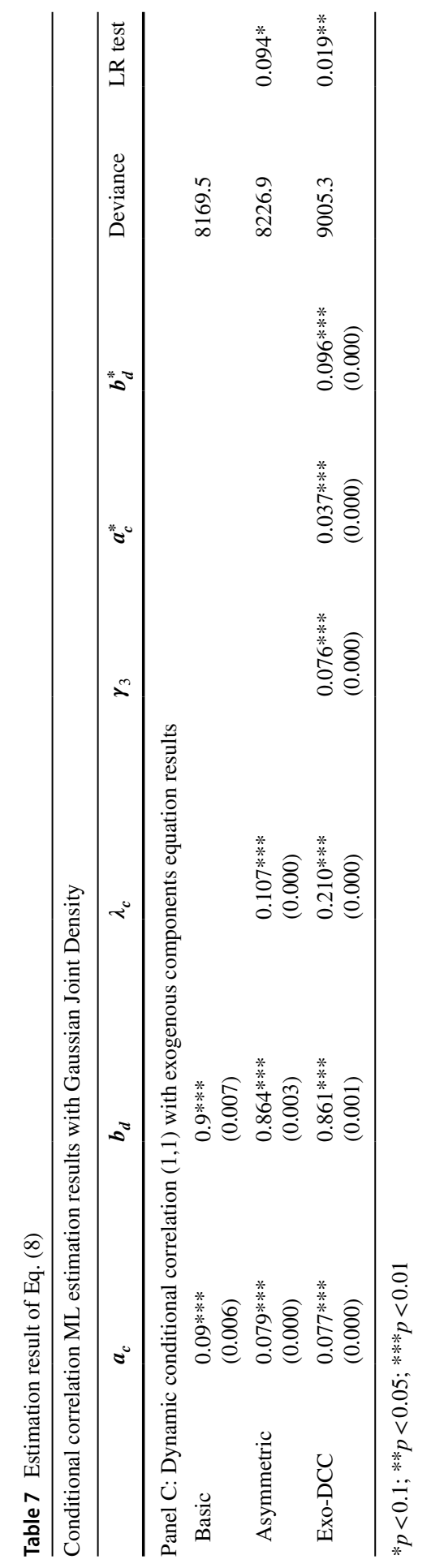


Publisher's Note Springer Nature remains neutral with regard to jurisdictional claims in published maps and institutional affiliations. 